\title{
Aleksandre Kazbegi’nin edebi metinlerinde halk ağzı kullanımı
}

\section{Gül Mükerrem ÖZTÜRK¹}

APA: Öztürk, G. M. (2020). Aleksandre Kazbegi'nin edebi metinlerinde halk ağzı kullanımı. RumeliDE Dil ve Edebiyat Araştırmaları Dergisi, (19), 745-751. DOI: 10.2900o/rumelide.752797.

\section{$\ddot{\mathbf{O} z}$}

Bu çalışma, XIX. yüzyılın ikinci yarısında Gürcü Klasik Edebiyatının en önemli isimlerinden biri olan Aleksandre Kazbegi'nin özgün çalışması olarak kabul edilen ve öne çıkan romanlarının edebi analizini kapsamaktadır. Kazbegi, eserlerinde Gürcü halk geleneklerinin yansımasına özellikle dikkat çekerek, yaratıcılığıyla yenilenen ve revize edilen dağcıların karakterlerini, gelenek ruhunu, kişisel ve ulusal özgürlük tutkularını temsil eden zengin folklorik dağ malzemesini kullanmaktadır. Yazarın çalışmalarının derin içeriği, zamana ve bölgeye göre değişen sınırsız sorunları yansıtmaktadır. Bilimsel literatürde ulusal efsanevi epik anlatıların bir

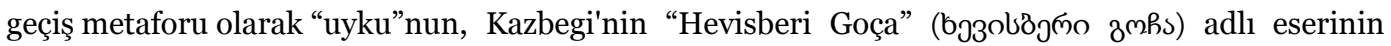

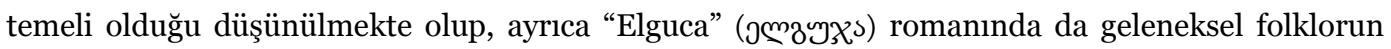
derin izleri görülmektedir. Bu romanında Gürcü dağcıların yaşamlarını, çevrelerini, ekonomik durumlarını, aile ve toplum yaşamlarının yer almasının yanı sıra konukseverlik, dini senkretizm, alışılmış hukuk, hasta bir insana saygı duyulması ve merhum için tutulan yas gibi bölümlere rastlamak mümkündür. Kazbegi'nin Elguca ve Svimon Çopikaşvili adlı çalışmasının ana karakterlerinin gerçek kişiler olması da önemlidir. Yazar, dağlık yaşamı anlatan bu romanında Moheve Ginca Huleli'nin ölümsüz yüzünü tasvir etmektedir. Roman, şiirler/sahneler, cenaze töreninde yapılan ağıtlar gibi geleneksel folklorik unsurlar içermektedir. Halk, geleneklerin güçlü bir savunucusudur. Eserde kovuşturma ve uzlaşma, ezeli düşmanlık şeklinde ifade edilmesinin yanı sıra kardeşlik vurgusu da yansıtılmaktadır. Romanın siyasi bir karakteri de mevcuttur. Aleksandre Kazbegi, "Moheveliler ve Yaşamları" adlı mektuplarında dağcıların yaşam tarzlarını, sonradan sanatsal eserlerinde yaygınlaşan geleneklerini de dile getirmektedir.

Anahtar kelimeler: Aleksandre Kazbegi, folklorik, Elguca, Hevisberi Goça, dağcıların yaşam tarzı

\section{The use of colloquial language in literary texts of Aleksandre Kazbegi}

\begin{abstract}
This study includes the literary analysis of the unique and prominent novels written by Aleksandre Kazbegi, one of the most important names of Georgian Classical Literature in the second half of the 19th century. The writer pays particular attention to the reflection of Georgian folk traditions. In his works, Aleksandre Kazbegi uses the rich mountain folkloric material which represents the characters and tradition spirit of the mountaineers and their personal and national passion for freedom by renewing and revising it with his creativity. The deep content of the author's works reflects unlimited problems by time and region. In the scientific literature, it is thought that "sleep" as a transition metaphor of national legendary epic narratives is the basis of Kazbegi's work named

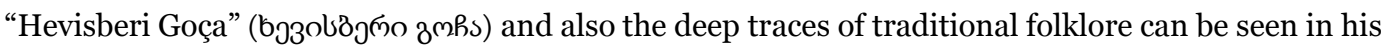

1 Dr. Öğr. Üyesi, Recep Tayyip Erdoğan Üniversitesi, Fen Edebiyat Fakültesi, Gürcü Dili ve Edebiyatı Bölümü (Rize, Türkiye), gul.ozturk@erdogan.edu.tr, ORCID ID: 0000-0003-4730-6720 [Makale kayıt tarihi: 09.05.2020-kabul tarihi: 20.06.2020; DOI: 10.29000/rumelide.752797] 
work named "Elguca" (gmaøx 3 ). In his novel "Elguca" the writer described the Georgian mountaineers' life, their environment, economic conditions, and family and community life. When reading the novel we come across with a number of interesting episodes of hospitality, religious syncretism, customary law, respect to a sick person and mourning over the deceased. It is also important that the main characters of Kazbegi's work titled Elguca and Svimon Çopikaşvili are real people. The author depicts the immortal face of Moheve Ginca Huleli in this story about the life in mountains. The story involves traditional folkloric elements such as poems / scenes and laments made at the funeral. The people are strong advocates of traditions. In addition to the fact that prosecution and reconciliation are expressed in an interesting way with eternal hostility, brotherhood is also emphasized in the work. The story also has a political feature. In his letters, "Moheves and their lives" Aleksandre Kazbegi describes the mountaineers' lifestyles and their traditions that later became common in their artistic works.

Keywords: Aleksandre Kazbegi, folkloric, Elguca, Hevisberi Goça, lifestyle of mountaineers

\section{Giriş}

Gürcü gerçekçiliğinin dikkate değer bir temsilcisi olan Aleksandre Kazbegi, Gürcü yazar Ilia Çavçavadze'nin edebi geleneklerinin halefisidir. Kazbegi, XIX yüzyılda Gürcistan'ın siyasal durumunu açıkça ifade ederek çalışmalarında Kafkas halkının Rus Çarlık otokrasisine karşı mücadelesini gösterir. Şiirsel ve nesir eserlerinde tarihsel gerçeklere dayanarak dağcıların yaşam resimlerini tasvir ederken, folklorik malzeme kullanır.

"Gürcü tarihi, edebi materyaller, hukuk kitaplarl, tarihi belgeler ve sanatsal eserler, Gürcülerin eski yaşam tarzı ve kültürünün incelenmesi için gerekli olan çeşitli bilgileri içerir. Bu açıdan Gürcü tarihçi,

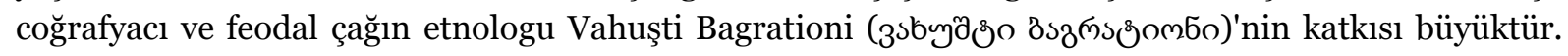
Bagrationi, varoluşsal olayların etnografik analizi ve yorumu ile yaptığı kapsamlı çalışmasında Gürcü ve Kafkas halklarının geleneklerinin incelenmesi için zemin hazırladı" (Bagrationi, 1973). Diğer yandan İlia Çavçavadze, Akaki Tsereteli, Vaja Pşavela, Aleksandre Kazbegi gibi ünlü Gürcü yazarlar bu geleneği XIX. yüzyılın ikinci yarısında da sürdürmeye devam etmişlerdir. Ancak Kazbegi, Gürcü edebiyatı ve Gürcü kültürü üzerinde kendini çalışmaya adayan bilim adamlarının sorunlarına bir yön çizmesi bakımından ve Gürcü edebiyatının geleneklerine bağlılığından dolayı önemli yer tutmaktadır.

\section{Aleksandre Kazbegi ve edebi yönü (1848-1890)}

Aleksandre Kazbegi'nin ataları feodalizm zamanında Hevi² bölgesinde büyük bir nüfusa hakimdiler. Vadiler, dağlar, geçitler bölgesi olan Hevi, Gürcistan'ın tarihi yerlerinden biridir. Kazbegi 20 Ocak

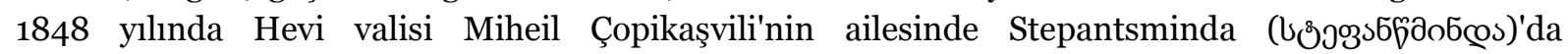
doğmuştur. On iki yaşına kadar ailesinin yanında eğitim gören Kazbegi, daha sonra Tiflis Lisesi'ne gönderilmiştir. Yazar, ilk öykülerini eğitiminde önemli rol oynayan dadısı Nino'ya adamıştır. İlk şiiri

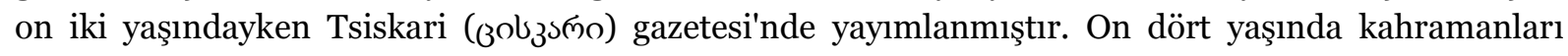
annesi ve babası olan "Eğitimciler" adlı bir komedi yazmıştır. Daha sonra bu komedisinde bazı değişiklikler yaparak, 1880 yılında sahnelenmiştir. Öğrencilik yıllarında çeviri faaliyetinde de bulunan Kazbegi, Shakespeare'nin Romeo ve Juliet'ini ve Lermontov'un birçok şiirini Gürcüceye çevirmiştir.

2 Hevi (’つว০), Gürcistan'ın kuzeydoğusundaki küçük bir tarihi-coğrafi bölgedir. Kazbegi ve Mtsheta-Mtianeti bölgesinde yer almaktadır. 
1863 yılında Moskova Ekonomi Akademisi'nde, 1867-1870 yılları arasında ise Klasik Spor Okulu'nda okumuştur.

Aleksandre Kazbegi, babasının ölümünden sonra Tiflis'e gitmiş ve Petrovsk-Razumovsk Ziraat Akademisine kaydolup eğitimine orada devam etmiştir. 1870 yllında ağır bir hastalığa yakalanarak ve memleketine dönmek zorunda kalmıştır. Kazbegi, köylülerin yaşamını daha iyi tanıyabilmek için dağlarda on yedi yıl çobanlık yaparak yaşamıştır. Yazarın doğanın içinde geçirdiği ve çobanlık yaptı̆̆ı bu yillar edebi yönünün gelişmesinde belirleyici olmuştur. Bu dönemde halkla iç içe olarak halkın gelenek ve göreneklerini, özlemlerini öğrenme olanağı bulmuş ve ayrıca yapıtlarına yarar sağlayacak sayısız halk efsanesi ve öykü dinlemiştir. 1879 yılında Hevi'den ayrılan yazar Tiflis'e dönerek yaşamını

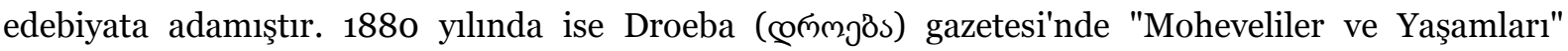

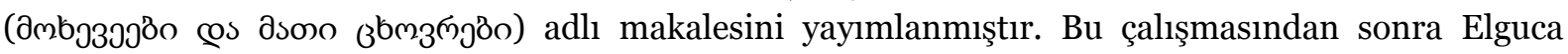

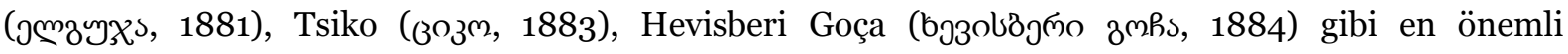
hikayelerini ve romanları basılmıştır.

Kazbegi'nin yapıtları halk yaşamına ve halk sanatına bağlıdır. Onun yapıtlarına hayat veren, düşüncelerine derinlik kazandıran her şey halktan esinlenilmiştir Kısacası, Kazbegi'nin yapıtlarındaki başlıca kahraman halktır. Yazar, dağlı insanları özgürlük tutkunu, dürüst, çalışkan ve yüzyllar boyunca geliştirilen ahlak kurallarına uyan insanlar olarak tasvir etmektedir. O yalnızca folklorik temalardan değil, halk sanatından alınmış anlatımlardan da yararlanmıştır.

Sanatsal düzyazı alanında büyük bir ustadır. Yapıtlarının içeriği karmaşık olsa da, dinamik bir anlatımı vardır. Ancak şunu da belirtmek gerekirse, Kazbegi, yapıtlarını okurlarına ulaştırmada Rus sansüründen dolayı zorluk da çekmiştir. Kazbegi, sadece bir tabloyu ya da bir olayı yansıtmakla kalmaz ayrıca kahramanlarının acılarını, sıkıntılarını ve neşelerini yaşama yeteneğine sahiptir. Kazbegi, birden şöhrete kavuşan bir yazardır. Elguca adlı romanını okuyan şair Grigol Orbeliani "Gürcü dilinde bugüne kadar böyle bir yapıt görülmemiştir" şeklinde dile getirmektedir (Kazbegi, 1948: 45). Yazar, tiyatroyla da ilgilenmiştir. Ancak yaşamının bu döneminde ağır bir hastalığa yakalanmış ve Tiflis'te 10

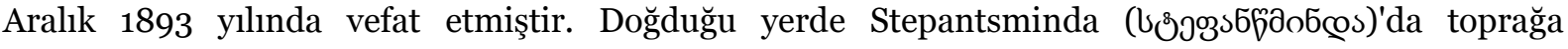
verilmiştir.

\section{Aleksandre Kazbegi'nin halk şiiri yönü}

Aleksandre Kazbegi'nin ilk çalışması üzerine Vardoşvili şöyle açıklamaktadır: "188o yllında "Droeba"

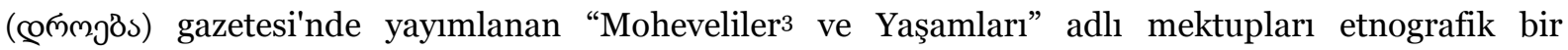
karaktere sahiptir. Mektuplarda yazar, dağcıların yaşamını, geleneklerini, göreneklerini ve manevi değerlerini ayrıntılı olarak açıllar ve daha sonra edebi eserlerinde genelleştirir" (Vardoşvili, 2010: 93).

Mektuplar A. Moçhubaridze takma adıyla yayınlanmıştır. Bu durum Kazbegi'nin eserlerinde folklorik malzemenin incelenmesi açısından ilginç kılmıştır. Araştırmacı M. Çikovani, mektupta iki konuya odaklanmaktadır. Buradan hareketle Aleksandre Kazbegi'yi dağ şiirinin yaratıcısı olarak şöyle açıklamaktadır:

"ilk olarak,

Yazar, çocukluğundan beri Mohevelilerin arasında bulunmuştur. Onların sıkıntılarının ve üzüntülerinin farkındaydı. Aleksandre Kazbegi'nin dağllk yaşamın cesur doğasına sahip olan insanlarla yakınlığı, folklorik ve sanatçllık yönü, hikayelerinde ve romanlarında şiirsel her bir

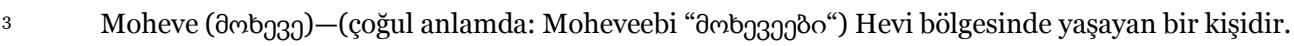

Adres

Kurklareli Üniversitesi, Fen Edebiyat Fakültesi, Türk Dili ve Edebiyatı Bölümü, Kayalı Kampüsü-Kırklareli/TÜRKIYE e-posta: editor@rumelide.com
Kurklareli University, Faculty of Arts and Sciences, Department of Turkish Language and Literature, Kayalı Campus-Kırklareli/TURKEY e-mail: editor@rumelide.com 
kelimenin nüansını duygusal olarak hisseden kadın - erkek, genç - yaşlı tüm kesimi kendine hayran bırakmıştır"

İkincisi ise,

Aleksandre Kazbegi coşkuyla topladı̆̆ dağ şiiri abidelerini derleyip yayımlamıştır. 1885 yılında şiirlerinin bir kısmı "İveria" (озэॅоం) dergisi'nde A. Moçhubaridze tarafından "Hevi'de Derlenen Halk Şiirleri” başlı̆̆ altında yayımlanmıştır. 1886 yılında Tiflis'te "Moheveliler ve Moheve şarkılarının halk şiirleri” adlı bir kitap yayımlandı. O zamanlar Kazbegi'nin yayımlanmaya hazır "Halk Şiirleri ve Aforizmaları" adlı çalışması da mevcuttu. Yayımlanan halk şiirleri dişında, Aleksandre Kazbegi'nin arşivinde el yazması formatında bazı dă̆ şiir örnekleri de yer almaktadır" (Çikovani, 1952: 157-158).

Güçlü bir ulusal yazar olmasına rağmen, eserleri genellikle Victor Hugo, Prosper Merimee, Andreas Gryphius gibi ünlü yazar ve şairlerin düzyazı eserleri ile karşılaştırılır. Kazbegi'nin eserlerinde folklorik unsurları incelerken, 1871 yılında birkaç ay önce Rusya'dan dönerek yazarın çoban olmasına ve 1879 yılına kadar dağlardaki diğer çobanlarla birlikte yaşadığı gerçeğine özel bir dikkat çekmeliyiz. Hayatının bu dönemini otobiyografik hikayesi olan "Çobanın Anıları"nda dile getirmiştir. "Çobanın Anıları" adlı hikayesini şu şekilde bitirmiştir:

"Bu mektupları yazmayı bıraktım, gördüklerimi ve duyduklarımı, nasıl duyduğumu ve nasıl anladığımı, size hikayeler olarak göstermeye ve Gürcistan'ın bir parçası olan ya da olmayan bu insanların geleneklerini, karakterlerini ve kurallarını size tanıtmaya çalıştım" (Kazbegi, 1976: 243).

"Çobanın Anıları"nda anlatılan dağcıların yaşamı, "Moheveliler and Yaşamları" adlı etnografik mektubunda anlatılan hikayeyle neredeyse aynı zamana denk gelmektedir.

\begin{abstract}
"18 yaşımda... Bir çoban olmaya karar verdim ve bu ticaretin yardımıyla dağların ve ovaların üzerinde yürümeye, insanlarla tanışmaya ve onlara her zaman eşlik ederek korkuyu ve zevki veren çoban hayatını hissetmeye karar verdim. Tabii ki, herkes, ilk adımlarıma güldü, çünkü asilzade ve saygın bir adamın oğlunun çoban olmasının uygun bir davranış olmadığını söylüyorlardı. Ama amacım, dileğim vardı ve bu isteğim o kadar güçlüydü ki kimsenin tavsiyesini dinlemedim: İnsanları görmek istedim, dileklerini öğrenmek istedim. Hayatlarını yaşamak, köylülerin taleplerini ve dertlerini hissetmek istedim ve hiçbir şey beni evde tutamazdı... Amacıma ulaştım, onlarla yakınlaştım, onlarla tanıştım, kısacası onlarla yakın arkadaş olmak ve tanışmak istedim" (Kazbegi, 1976: 212).
\end{abstract}

\title{
Aleksandre Kazbegi'nin düz yazı (nesir) eserlerinde folklor
}

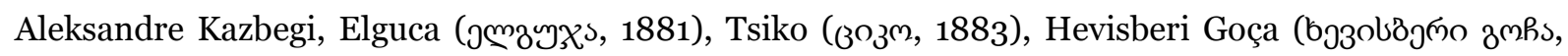
1884) adlı eserlerinde dağcıların yaşamını sosyal bir dille samimi duygularını açıklayarak anlatmıştır. $\mathrm{O}$, insanların yaşamlarıyla bağlantılı olarak doğayı göstermiş̧ir.

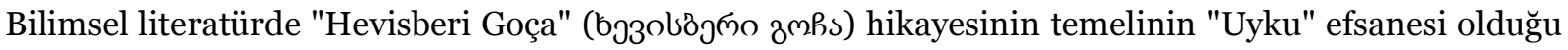
düşünüldüğünde bunun çeşitli versiyonları vardır. Moheveli Ginca Huleli, bu hikayeyi Kazbegi karakterini "Elguja" (gмзðð১) da tasvir ettiği yazarı anlatır. "Hevisberi Goça", Kazbegi'nin eserlerinin zirvesidir ve sanatsal yorumu ile Shakespeare'in gerçekçilik ruhuyla bağlantılıdır. Bu hikaye, genellikle Prosper Merimee "Mateo Falcone" ile karşılaştırılır.

Hikâyenin tarihi temeli, XVI. yüzyılın sonu ve XVII. yüzyılın başında yaşayan Nugzar Eristavi'nin, dağclların güçlü bir direnişiyle sonuçlanan özgür Hevi'yi yönetme isteğine dayanmaktadır.

Hikâye, düğün ile ilgili ritüel sahnelerinin tasviriyle başlar. 


\begin{abstract}
"Misafirler, insanlarla dolu eve girdiler. Yaşlı insanlar onları karşıladılar ve damadın yolunu kutsadılar, ocağın etrafında damada yer açtılar. Damadı evin en yaşlı kișisiyle birlikte ocağın yanına oturttular. Ayakta duran insanlar da oturdu ve ziyafetlerine devam ettiler. Her zamanki gibi kadehler kaldırdılar. Ancak burada sadece erkekler vardı, kadınlar hiç bir yerde gözükmüyordu. Onların sesleri evin arka köşesinden geliyordu ve orada dans ediyorlardı. Genç

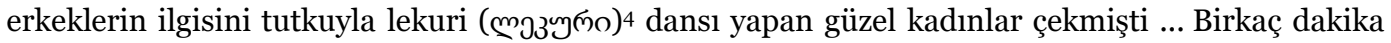
sonra, yaşlı bir kadın aralarından belirdi. Herkes ayağa kalktı ve doğrudan damada doğru yaklaşan yaşlı kadını herkes selamladı ve yaşlı kadın damada sarılarak ona şöyle söyledi: - Benim her şeyim, küçük kızım sana emanet ... Ona göz kulak ol, onu koru, onu üzenleri üzmelisin!" (Kazbegi, 1976: 253-254).
\end{abstract}

Hikâyede Moheveli Gugua, kızı Dzidzia'yı Hevisberi Goça'nın tek oğlu olan Onise ile evlendirir. Onise ve Dzidzia birbirlerine çok aşıktırlar. Onise'nin sevgisi günden güne körelmeye başlar. Ancak sonunda bu aşkın sonu trajik biter ve Hevisberi Goça, oğlunu kendi elleriyle öldürür. Ancak mahkemeye sevk edilen Goça, beraat eder ve böylece Mohevelilere ihanetle suçlanmaz. Ancak oğlunu öldüren Hevisberi Goça aklını yitirir, Dzidzia ve Gugua da vefat eder.

"Dua" sahnesi etkileyici bir şekilde anlatılmıştır:

\begin{abstract}
"Moheveliler önemli bir konuda karar vermek için kilisenin bahçesinde toplanmışlardı. Önce kilisenin eskrimden oluşan bayraktaki haç belirdi, sonra da tüm bayrak ortaya çıtı. Aynı anda insanlar dizlerinin üzerine çöküp haç işareti yaparak dua ettiler. Uzun gri saçlı ve şapkasız sakallı bir adam duvarda belirdi... Yaşlı adam bayrağa dokundu ve küçük çanların sesi tam bir sessizlik içinde duyuldu... Goça bir kez daha bayrağa dokundu, sonra bir kez daha çanlar çalındı ve insanlar sessizce, tatlı ve telaşsız şekilde kutsamaya başladılar. Goça, daha sonra kendilerini köye adamış ve halkının refahı için ellerinden geleni yapanlar içinde kutsamaya başladı. Daha sonra ellerini kaldırarak Tanrı'ya dua ederek kutsamasını bitirdi, Hevi'den vazgeçmedi ve sonsuza dek orası tüm belalardan koruyucusu oldu" (Kazbegi, 1976: 284).
\end{abstract}

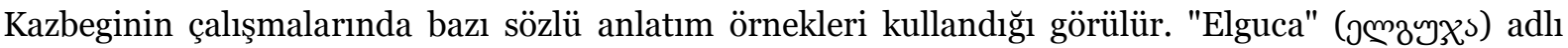
romanında sözlü anlatımın derin izleri görülmektedir. Siyasi bir içeriye sahip olan roman 1804'teki Mtiuleti ayaklanmasının 5 tarihi gerçeklerini ortaya çıarmıştır. Yüksek Komiser Pavle Tsitsianov zamanında isyancılar Gürcistan Askeri Yolu'nu fethetmişlerdir ve amaçları, Gürcistan tahtına çıkmak olan İran'a sürgün edilen Aleksandre Batonişvili ile temasa geçmektir. Aleksandre Kazbegi, insanların Rusya'ya ve siyasi çıkarlarına karşı tutumunu şu şekilde açılamaktadır:

"Gürcistan Rusya'nın koruması altında! Bu ses bir darbe gibiydi, çünkü Rusya'nın korunmasını diledik ve aniden onun kölesi olduk... Ve böylece Pasanauri köyünün dar yerlerinden on gün içinde geçecek olan Rus askerlerinin yolunu kapatacaklarına karar verdiler, artık daha ileri gidemediler ve geri döndüler. Moheveliler de Dariali Geçidi'ni engelleyeceklerini ve kimsenin geçemeyeceğini kabul ettiler" (Kazbegi, 1976: 113).

Romanın ana karakterleri olan Elguca ve Svimon Çopikaşvili gerçek kişilerdir. Hevi'de, Elguca Pashateli'nin bir kadını kaçırdığına dair bir efsanedir. Elguca hakkında Hevi bölgesinde geçen folklorik şiirler de mevcuttur. Birçoğunun romanın içinden gelmesi de dikkat çekicidir. Kazbegi'nin eserlerinde ilginç bulduğumuz bir durum söz konusudur. Romanlarının karakterleri Kafkasya'daki farklı ulusların çocuklarıdır ve dinlerinin yanı sıra etnik kökenleri de birbirinden farklıdır. Kazbegi, eserlerinde farklı dinlere ve etnik kökene vurgu yapmaktadır. Ayrıca dostluk, sevgi, özgürlük ve mücadele gibi evrensel değerlerden bahsederken, karakterler arasında sınırlama yoktur ve aynı fikre sahiptiler.

Lekuri (мэзэю̆о): Çeçenlerce Lovzarg, Kabardeylerce Islamey, Osetlerce Zilga, Azerilerce Qaytağı, İnguşlarca Halhar ve Kafkasya dışında Şeyh Şamil ya da Lezginka olarak bilinen bir halk dansıdır.

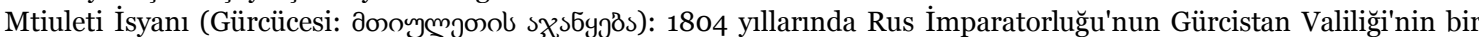
parçası olan eski Kartli-Kaheti Krallığı'nda gerçekleşen bir çatışmadır. Rus yönetimine yönelik ilk büyük Gürcü isyanıdır.

Adres

Kırklareli Üniversitesi, Fen Edebiyat Fakültesi, Türk Dili ve Edebiyatı Bölümü, Kayalı Kampüsü-Kırklareli/TÜRKİYE e-posta: editor@rumelide.com 
Kazbegi, genellikle "Elguca" ( эmзэх১) adlı eserinde folklor efsanelerini ve atasözlerini kullanır ve eserlerindeki kullanımları, bazı geleneklerin açıklamasıyla sentezlenir. Dünya literatüründe de buna benzer örnekler mevcuttur. Metne baktığımızda, "Haklısın, haklısın! Eğer günü geldiyse, bizim de ölmemize izin ver. Bir erkek bir kez doğar ve bir kez ölür." (Kazbegi, 1976: 66). Dağcllar hasta Elguca'ya bu şekilde hitapta bulunurlar ve böylece adaletsizliğe karşı cesaretlerini kanıtlarlar. Ya da "Yara izi olan bir adamın daha iyi olduğu ve normal bir kadının, yüzünde hiç yara izi olmayan bir adamla evlenmeyeceği insanlar olmalıydı" (Kazbegi, 1976: 67) şeklinde dile getirilmektedir.

Bu çalışmada, yemin kardeşliği ve dostluğu görebiliriz. Moheveliler, Mtiuli Rus askerlerine karşı savaşmadan önce kardeşlik yemini ederler. Hepsinin bir olması, biri diğerinin adına hareket etmesi ve diğerinin de her şey için kendi feda etmesi gibi.

"Fakat bu yemine gerek yoktu. Çünkü onlar birbirlerine yardım etmeyi ve birbirleri için kendini feda etmeyi bir görev olarak görüyorlardı. Anne sütü emen ve arkadaşlarının ihanetine karşı nefret besleyen insanlarda böyle olması gerekirdi. Bu insanların peri masalları ya da şiirler tarzında konuları vardı ve böylece güçlü bir bakış açısını aşılamış oldular" (Kazbegi, 1976: 118-119).

Aleksandre Kazbegi, Hevi'nin halk şairi Ginca Huleli'nin ölümsüz yüzünü de resmetti. Yazdığı şiirlerden bazıları eserde kullanılmıştır. "Yazar onu şahsen tanıyordu ve şiirlerini de yazıyordu, özellikle Kral Erekle hakkındaki ünlü halk yas şiiri "Büyük Kahramanı Diriltmek" (Çavleişvili, 1985: 82). "Ginca Huleli, XIX. yüzyılın ikinci yarısında yaşamış gerçek bir kişidir. Ginca, 1881 yllında "Elguca" (эmзðx১) romanı kaleme alındığı sıra yaşlıydı ve geleneksel edebiyatın büyük bir uzmanı ve usta yorumcusuydu" (Çikovani, 1952: 160).

\section{Kazbegi, Ginca Huleli'yi şu şekilde karakterize eder:}

"Svimon ile yaşlı Ginca oturuyorlardı ... Ginca, dağlarda ünlü bir pandurí ${ }^{6}$ çalgıcısı, duygu dolu ve esprili bir şairdi. Bu nedenle, herkes ona saygı duyardı. Çünkü sevilen bir konuk, tatlı sesli, duygu doluydu. Ginca, pandurinin tellerine her dokunduğunda panduri öyle bir ses çıkarıyordu ki, bir adamın kalbine işliyor, ürpertiyor ve terletiyordu" (Kazbegi 1976: 156).

Romanda toplumun eski geleneklerini korumak için elinden gelenin en iyisinin yapıldığı gösterilmesine rağmen toplumun bozulduğunu da görebiliriz. Tüm önemli konular toplumun en yaşlı insanları tarafından mantık çerçevesinde karar verilir. Yeminli düşmanın hükmü ve uzlaşması ilginç bir şekilde anlatılır. Elguca ve Svimon Çopikaşvili konusu halk tarafından eleştirilir ve Gagi'nin Elguca tarafından öldürülmediğini gördüklerinde Çopikaşvili'nin intikam almaması gerekir. Konsey, Mzağo'nun kaçırılmadığını ve Elguca ile kendi isteğiyle gittiğini göz önünde bulundurur. Bu durum toplumun demokratik ve insani ilkelere bağlı olduğunu açıç̧a göstermektedir. Ancak, halk kararın yerine getirilmesini ister:

"Gagi'nin uçurumdan düşmesi Elguca'nın onu öldürdüğü anlamına gelmez. Ondan intikam almaman gerekir. Bunun yerine Elguca'nın topraklarına el konulacak ve Svimon Çopikaşvili'ye verilecek... Svimon dolayısıyla Elguca'nın tıbbi tedavisini ödeyecek. Elguca'nın akrabaları, toplum huzuruna Gagi'nin mezarına bir boğa ve ayıyla çıkması ve mezarında özür dilemesi gerekmektedir. Kadın, satın alınarak Svimon'un yanında kalmalı ve Elguca onu almak isterse 40 inek ile cezasın ödemelidir. Bundan sonra Elguca ve Svimon artık birbirleriyle iyi bir kardeş ve iyi bir komşu olması gerekir. Birbirlerini sevmek zorundalar" (Kazbegi, 1976: 79). 
Cenaze töreninde yapılan yas ve yüksek sesle yapılan ağıt gibi bazı geleneklerin sahneleri romanda yer almaktadır. Hasta olan Svimon Çopikaşvili'nin ölümünden sonra:

\begin{abstract}
"Ölü yıkandı, en iyi kıyafetleri giydirilmiş, tıraş edilmiş ve odaya götürülmüştü. Yas tutanlar ve kederli akrabaları onun etrafındaydı, ama bir kișide cenazenin başında duruyordu... Çoğunlukla orta yaşlı kadınlar vardı, omuzlarında şallar vardı ve kollarını sıvadılar, ağıt yakmaya hazırdılar. Köyün kadınlarından dağlıların karakteristik ağlama şekli duyuldu... Bu olay yedi gün boyunca devam etti. Evdeki yaşlı kadınlardan biri, ölünün göğsünden silahı aldı, üzerine eğildi ve şiirlerinde de ölülerin hayatını anlattı, diğer insanlar ise onun hayatını yas tutmaya başladılar. Zaman zaman diğer yas tutanlar da gözyaşlarına boğuldular. Ölülerin adı ile birlikte, kayda değer bir iş yapmış diğer ölülerin isimleri de asla unutulmadı" (Kazbegi, 1976: 166).
\end{abstract}

Yukarıda belirtilen örnekler ışığında Kazbegi'nin Moheve geleneklerini ve göreneklerini yaratıcılığıyla yenilenen ve revize edilen dağcıların karakterlerini, gelenek ruhunu, kişisel ve ulusal özgürlük tutkularını açıkça gösteren folklorik dağ unsurlarını kullandı̆̆ını söyleyebiliriz.

\title{
Sonuç
}

Aleksandre Kazbegi'nin "Elguca" adlı romanı, Moheveli Elguca ve Çerkes kadın Mzağo arasındaki dostluğun ve kahramanlığın arka planında gelişen aksiyon dolu roman olarak atfedilmektedir. Roman, kahramanların manevi dünyasını ifade etmesi için bir arka plandır. Bu romanında yazar, dağcıların gelenek ve göreneklerini göstermek için folklorik malzeme kullanmıştır.

Aleksandre Kazbegi, "Hevisberi Goça" adlı hikayesinde ise Mohevelilerin yaşamı için karakteristik ritüel sahnelerini ve geleneklerini folklorun sözlü anlatım ve efsane örneklerine dayandırarak anlatır. Hikaye, psikolojik bir karaktere sahiptir ve yazar bize derin bir trajedi ile kahramanların maceralarını anlatır. Daha önce de bahsettiğimiz gibi, Kazbegi, etnografik ve otobiyografik öykülerinde genellikle folklorik materyal kullanır.

Diğer taraftan; bu çalışma, dağcılık geleneklerinin yüzyıllar boyunca insanların bilincinde sağlam bir şekilde yer aldığını, bireyin farklı sosyal durumuyla bile düzensizleştirilemeyeceğini açıça yansıtmaktadır. Kazbegi'nin bakış açısına göre Mokheve gelenekleri, ilişkilerin güçlendirilmesinde, köy nüfusunun ve toplum üyelerinin yakınlaşmasında, halklar arasında hayırseverlik ilişkilerin kurulmasında da önemli rol oynamıştır. Kendi bölgesine ve halkına yakınlık duyan Kazbegi'nin hala bilimsel çalışmalara konu olması, yaratıcı çalışmalarının sonsuzluğunu göstermektedir. Sonuç olarak, Kazbegi'nin edebi mirasını incelemek için birçok bilimsel eser olmasına rağmen, bu çalışmanın da Kazbegi üzerine yapılacak olan daha sonraki bilimsel çalışmaların bakış açlarına ve yaklaşımlarına kaynak oluşturacağı düşünülmektedir.

\section{Kaynakça}

Bagrationi, V. (1973). Simon Kaukhchishvili'nin Yorum ve Görüşleri. Gürcistan Tarihi, Gürcü Krallĭ̆ Dergisi. Cilt :4, 65-67.

Çavleişvili, T. (1985). Kazbegi'nin "Elguca" Romanının Yaratıcllk Tarihi. Creative history of Kazbegi's "Elguja”. Tiflis: Publishing House "Science".

Çikovani, M. (1952). Gürcü Halk Edebiyatı Çalışmaları Tarihi. Tiflis: Publishing House Of Scientific Methodical Cabinet.

Grişaşvili, İ. (1987). Takma İsimler Sözlüğü. Tiflis: Nişaduri Yayınevi.

Kazbegi, A. (1948). Aleksandre Kazbegi ve Eserleri. 4. Cilt, Tiflis: Sabçota Mtzerali Yayınevi.

Kazbegi, A. (1976). Hikâyeler. Tiflis: Publishing House "Nakaduli". 
756 / RumeliDE Journal of Language and Literature Studies 2020.19 (June)

The use of colloquial language in literary texts of Aleksandre Kazbegi / G. M. Öztürk (pp. 745-751)

Vardoşvili, E. (2010). Poetic Coincidences. Tbilisi: Polygraphic Center "Barton".

Yerguz, İ. (1997). Aleksandre Kazbegi. Mamuli Kültürel Dergi. Sayı: 4, 7-10. 